\title{
Modest Hypothermia Provides Partial Neuroprotection for Ischemic Neonatal Brain
}

\author{
ABBOT R. LAPTOOK, RON J. T. CORBETT, RICK STERETT, DENNIS K. BURNS, \\ GREG TOLLEFSBOL, AND DAMIAN GARCIA \\ Departments of Pediatrics [A.R.L., R.S., G.T., D.G.], Radiology [R.J.T.C.], and Pathology [D.K.B.], \\ University of Texas-Southwestern Medical Center at Dallas, Dallas, Texas 75235
}

\begin{abstract}
Hypothermia is a frequent occurrence in newborns, and thermoregulatory management is a fundamental part of medical stabilization. Although modest reduction in brain temperature $\left(2-3^{\circ} \mathrm{C}\right)$ before ischemia provides neuroprotection in adults, the effect of modest hypothermia on immature brain has not been examined. Nineday-old swine were exposed to $15 \mathrm{~min}$ of incomplete global brain ischemia, with intraischemic rectal temperatures of either $38.3 \pm 0.4^{\circ} \mathrm{C}(n=10$, normothermic) or $35.4 \pm$ $0.5^{\circ} \mathrm{C}(n=10$, hypothermic). The relationship between rectal and brain temperature was delineated in preliminary experiments on four swine. Animals with intraischemic rectal temperatures maintained at either $39.5^{\circ} \mathrm{C}$ or $35.5^{\circ} \mathrm{C}$ were associated with a similar magnitude of difference in brain temperature. Therefore, rectal temperature was used to monitor brain temperature for $\mathbf{2 0}$ animals studied subsequently. Ischemia was induced by combining neck compression with hemorrhagic hypotension and resulted in similar group values for mean arterial pressure and changes in $\mathbf{p H}$ and blood gases at the completion of ischemia. $\mathbf{A}$ clinical overall performance score and brain tissue structure were evaluated after $72 \mathrm{~h}$ (or earlier if animals died prematurely). Hypothermic animals had less severe stages of impairment compared with the normothermic group ( $p$ $=0.023$ ). Hypothermic piglets had less histologic damage in the neocortex at $0.5 \mathrm{~cm}$ beneath the brain surface $(p=$ $0.048)$, the caudate nucleus $(p=0.038)$, and the pons/ midbrain $(p=0.04)$ and the same direction of effect in neocortex at $1 \mathrm{~cm}$ beneath the surface $(p=0.07)$ and the cerebellum $(p=0.07)$ as compared with normothermic animals. The results demonstrate that a $2-3^{\circ} \mathrm{C}$ reduction in brain temperature during $15 \mathrm{~min}$ of incomplete ischemia provides partial neuroprotection in neonatal swine. (Pediatr Res 35:436-442, 1994)
\end{abstract}

\section{Abbreviations}

OPS, overall performance score

MAP, mean arterial pressure

CBF, cerebral blood flow

Profound hypothermia during complete circulatory arrest has a protective effect on brain tissue structure and neurologic function $(1,2)$. Recently, a resurgence of interest has occurred in the neuroprotective effects of more modest reductions in tempera-

Received March 11, 1993; accepted December 7, 1993.

Correspondence and reprint requests: Abbot R. Laptook, M.D., Department of Pediatrics, UT-Southwestern Medical Center at Dallas, 5323 Harry Hines Blvd., Dallas, TX 75235-9063.

Supported by the United Cerebral Palsy Research and Educational Foundation, Inc. and the Department of Pediatrics, UT-Southwestern Medical Center at Dallas. ture. Busto et al. (3) and others $(4,5)$ have demonstrated that a $2-3^{\circ} \mathrm{C}$ reduction in intraischemic brain temperature of adult animals markedly attenuated neuropathologic changes. These observations were independent of the manner in which the brain was cooled. Modest hypothermia during ischemia resulted in different degrees of neuroprotection in different brain regions (3, 6). Thus, small changes in brain temperature may contribute to some of the inconsistencies in the literature regarding the effects of pharmacologic agents and the impact of brain ischemia on neurologic outcome.

A paucity of information on neonates exists regarding the neuroprotective effects of modest hypothermia. The effects of hypothermia on brain tissue structure was examined in 7-d-old Sprague-Dawley rats subjected to hypoxia-ischemia for $3.5 \mathrm{~h} \mathrm{(7)}$ At an ambient temperature of $37^{\circ} \mathrm{C}$, hypoxia-ischemia resulted in extensive brain infarction, but no histologic injury occurred at $21^{\circ} \mathrm{C}$, and at $29^{\circ} \mathrm{C}$ damage was limited to focal areas of necrosis. These observations have recently been extended to 10 d-old Sprague-Dawley rats subjected to hypoxia-ischemia, where reduction in axillary temperature by $2.5^{\circ} \mathrm{C}$ reduced the incidence of brain damage (8). However, core body and brain temperature were not measured. Despite the limited information, modest hypothermia is especially attractive as a potential therapeutic modality in the neonatal period. Newborns are prone to excessive heat loss resulting from sparse thermal insulation and a relatively large surface area in relationship to body mass. These processes are exacerbated at birth by large evaporative and nonevaporative heat losses normally occurring from a newborn's warm, wet skin. The latter can result in core body temperature falling by $2^{\circ} \mathrm{C}$ in the first $30 \mathrm{~min}$ after birth (9). Modest hypothermia could be used as part of the approach to improve recovery of an infant in need of resuscitation in the delivery room. It is often unclear at the time of birth whether an hypoxic-ischemic event has previously occurred or whether difficulty in the transition from in utero to extrauterine environments results in a hypoxic-ischemic interval in the immediate postnatal period. Thus, ample justification exists for evaluation of modest hypothermia as a protective measure (during ischemia) and as a resuscitative strategy (after ischemia). The purpose of this investigation was to examine the neuroprotective effects of modest hypothermia applied during partial ischemia in neonatal swine brain.

\section{MATERIALS AND METHODS}

Surgical preparation. This investigation was approved by the Institutional Review Board for Animal Research at The University of Texas Southwestern Medical Center at Dallas. A total of 27 piglets were studied. Twenty-three piglets were administered ketamine $(20 \mathrm{mg} / \mathrm{kg}$ intramuscularly) as premedication and then instrumented under pentobarbital anesthesia $(20 \mathrm{mg} / \mathrm{kg}$ via ear vein). Catheters were positioned by aseptic technique in the internal and external jugular vein and the left common carotid artery. Catheters were tunneled s.c. to the piglet's back and stored 


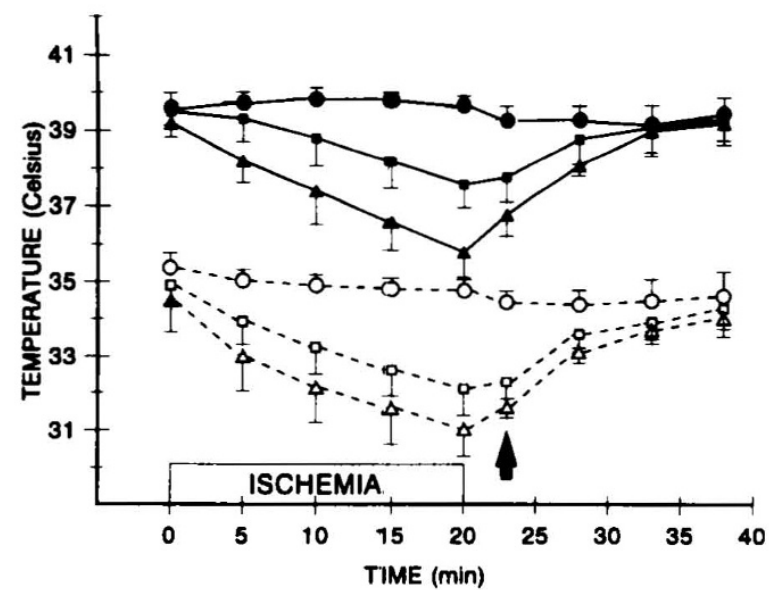

Fig. 1. The relationship between rectal (circles) and brain temperature (triangles and squares for temperatures at depths of 1 and $2 \mathrm{~cm}$, respectively) during and after ischemia for four piglets studied at rectal temperatures of $39.5-40^{\circ} \mathrm{C}$ (solid symbols) and $35-35.5^{\circ} \mathrm{C}$ (open symbols). During ischemia, brain temperature recorded at depths of 1 and 2 $\mathrm{cm}$ beneath the cortical surface decreased. Comparing animals with different intraischemic rectal temperature revealed that the magnitude of reduction in brain temperature was similar at a depth of $1 \mathrm{~cm}$ but was significantly greater at $2-\mathrm{cm}$ depth among animals with a rectal temperature of $35^{\circ} \mathrm{C}(p<0.025)$. After ischemia, deflation of the pressure cuff and blood reinfusion was completed within 3 min (arrow). Within the next $10 \mathrm{~min}$, brain and rectal temperature closely approximate each other for animals maintained with rectal temperatures of either $39.5^{\circ} \mathrm{C}$ or $35.5^{\circ} \mathrm{C}$.

in a pouch. When the animals recovered from anesthesia, gavage or pan feeding with sow replacement milk was initiated. Aseptically instrumented piglets $(n=23)$ were studied $24 \mathrm{~h}$ after surgery. Preparation for experiments included the use of pentothal $(20 \mathrm{mg} / \mathrm{kg}$ i.v. $)$ to facilitate oral intubation and mechanical ventilation with inspired gases of $70 \% \mathrm{~N}_{2} \mathrm{O}$ and $30 \% \mathrm{O}_{2}$. Muscle paralysis and analgesia were achieved with vecuronium $(0.25$ $\mathrm{mg} / \mathrm{kg} / \mathrm{h}$ i.v. $)$ and nubain $(0.15 \mathrm{mg} / \mathrm{kg}$ i.v. $)$, respectively. Rectal temperature was monitored with a thermocouple microprobe inserted to a depth of $5 \mathrm{~cm}$, and a blood pressure cuff was positioned around the animals neck.

In four piglets, acute instrumentation, including tracheostomy, catheter placement, and creation of a burr hole, was performed as previously described (10). The latter four piglets were used for preliminary studies to measure rectal and brain temperature with thermocouple microprobes $(0.64 \mathrm{~mm}$ diameter, Physitemp Instruments, Clifton, $\mathrm{NJ}$ ) implanted to depths of 1 and $2 \mathrm{~cm}$ within brain tissue via a burr hole, which was then sealed with bone wax.

Experimental design. For the 23 aseptically instrumented piglets, a 60-90 min stabilization interval was followed by a control period of $20 \mathrm{~min}$ to acquire duplicate blood samples and measurement of physiologic variables with maintenance of rectal temperature between 38 and $38.5^{\circ} \mathrm{C}$ in all animals. After the control period rectal temperature was reduced approximately $2.5^{\circ} \mathrm{C}$ in 10 animals (modest hypothermia, age $9 \pm 3 \mathrm{~d}$ ) and maintained normothermic in 10 piglets (normothermic, age $9 \pm$ $3 \mathrm{~d})$. Rectal temperature was altered by changing the temperature of water circulating through a thermal blanket wrapped around the piglets. Once the reduction in temperature was achieved, brain ischemia was induced during an interval of $10 \mathrm{~min}$ by gradual inflation of the blood pressure cuff around the neck to $40 \mathrm{kPa}$, and hemorrhage via a venous catheter to an MAP of 4 $\mathrm{kPa}$. As demonstrated previously this technique results in a 60$70 \%$ reduction in cerebral blood flow (11). Each animal was infused with glucose $(10 \mathrm{mg} / \mathrm{kg} / \mathrm{min}$ i.v.) during ischemia to insure similar intraischemic plasma glucose concentration, and ischemia was maintained for $15 \mathrm{~min}$. Ischemia was reversed by deflation of the blood pressure cuff, rapid reinfusion of all withdrawn blood, and termination of the glucose infusion. Rectal temperature was quickly raised in the modestly hypothermic group at the completion of ischemia by appropriate adjustment of the thermal blanket temperature. Thereafter, rectal temperature was maintained normothermic in both groups. A postischemic interval lasted $60 \mathrm{~min}$, after which animals were weaned from the ventilator, extubated, and returned to their pens. A clinical neurologic assessment was performed at 24,48 , and 72 $\mathrm{h}$ after ischemia. Care of the animals during this interval consisted of daily flushing of vascular catheters, free access to artificial sow replacement milk, and gavage feeding if self-feeding was not observed. Three of the 23 piglets were used as sham-operated controls and underwent identical instrumentation and experimental observation without brain ischemia.

Physiologic and biochemical assessments and OPS. MAP, heart rate, and arterial blood samples for blood gases, $\mathrm{pH}$, hematocrit, and plasma concentrations of glucose and lactate were measured as previously described (10). Blood samples were obtained in duplicate at control; at 4 and 12 min during the ischemic interval; at 5, 30, and $60 \mathrm{~min}$; and at $72 \mathrm{~h}$ after ischemia. An additional blood sample was obtained for the modestly hypothermic group after temperature reduction but before ischemia. The neurologic evaluation of piglets was standardized with the OPS developed at the Resuscitation Research Center, University of Pittsburgh (12). The OPS evaluates the state of awareness; ambulatory abilities; muscle tone; abnormal movements; presence or absence of hyperventilation and seizures; response to noise, pain, and light; and the ability to feed. These scores

Table 1. Physiologic variables before, during, and after brain ischemia in normothermic and modestly hypothermic piglets

\begin{tabular}{|c|c|c|c|c|c|c|}
\hline & \multirow[b]{2}{*}{ Control } & \multicolumn{2}{|c|}{ Ischemia } & \multicolumn{3}{|c|}{ After ischemia } \\
\hline & & $4 \mathrm{~min}$ & $12 \mathrm{~min}$ & $5 \mathrm{~min}$ & $30 \mathrm{~min}$ & $60 \mathrm{~min}$ \\
\hline \multicolumn{7}{|c|}{ Rectal temperature $\left({ }^{\circ} \mathrm{C}\right)$} \\
\hline Normothermic & $38.3 \pm 0.2$ & $38.4 \pm 0.4$ & $38.3 \pm 0.4$ & $37.5 \pm 0.3$ & $38.3 \pm 0.3$ & $38.3 \pm 0.2$ \\
\hline Hypothermic & $38.3 \pm 0.3$ & $35.4 \pm 0.5^{*}$ & $35.4 \pm 0.5^{*}$ & $35.5 \pm 0.8^{*}$ & $37.5 \pm 1.3$ & $38.3 \pm 0.2$ \\
\hline \multicolumn{7}{|l|}{$\operatorname{MAP}(\mathrm{kPa})$} \\
\hline Normothermic & $12 \pm 2$ & $5 \pm 1$ & $4 \pm 1$ & $13 \pm 1$ & $11 \pm 2$ & $10 \pm 1$ \\
\hline Hypothermic & $12 \pm 2$ & $4 \pm 1$ & $4 \pm 1$ & $14 \pm 3$ & $12 \pm 2$ & $11 \pm 1$ \\
\hline \multicolumn{7}{|l|}{ Arterial pH } \\
\hline Normothermic & $7.44 \pm 0.05$ & $7.30 \pm 0.06$ & $7.21 \pm 0.05$ & $7.21 \pm 0.10$ & $7.31 \pm 0.08$ & $7.39 \pm 0.05$ \\
\hline Hypothermic & $7.42 \pm 0.05$ & $7.37 \pm 0.08$ & $7.24 \pm 0.09$ & $7.23 \pm 0.08$ & $7.33 \pm 0.07$ & $7.38 \pm 0.06$ \\
\hline \multicolumn{7}{|c|}{ Arterial lactate (mM) } \\
\hline Normothermic & $0.8 \pm 0.2$ & $5.7 \pm 2.2$ & $7.4 \pm 2.2$ & $7.8 \pm 1.6$ & $5.3 \pm 1.3$ & $3.1 \pm 1.1$ \\
\hline Hypothermic & $0.9 \pm 0.2$ & $4.6 \pm 1.9$ & $6.8 \pm 2.4$ & $6.3 \pm 1.4$ & $3.8 \pm 0.9 \dagger$ & $2.5 \pm 0.9$ \\
\hline
\end{tabular}

$* p<0.0001$ for normothermic $v s$ hypothermic.

$\dagger p=0.0033$ for normothermic $v s$ hypothermic. 
Table 2. Distribution of overall performance scores*

\begin{tabular}{lccccc}
\hline & Normal & $\begin{array}{c}\text { Mild } \\
\text { encephalopathy }\end{array}$ & $\begin{array}{c}\text { Moderate } \\
\text { encephalopathy }\end{array}$ & $\begin{array}{c}\text { Severe } \\
\text { encephalopathy }\end{array}$ & $\begin{array}{c}\text { Brain } \\
\text { dead }\end{array}$ \\
\hline Normothermia $(n=10)$ & 3 & 1 & 1 & 5 & 0 \\
Modest hypothermia $(n=10)$ & 7 & 2 & 0 & 1 & 0 \\
\hline
\end{tabular}

* $p=0.023$ for comparison of groups.
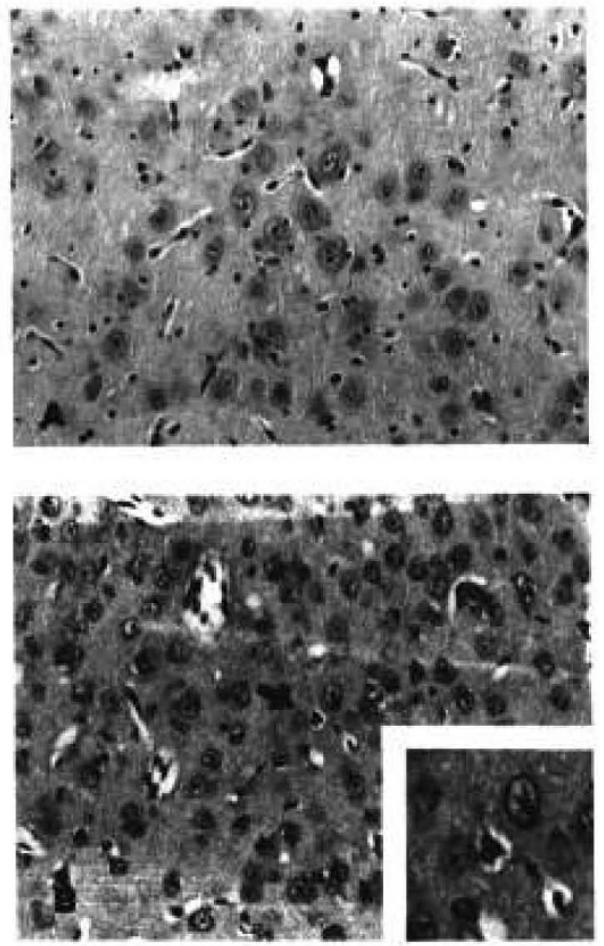

Fig. 2. A, Photomicrograph of cerebral neocortex from a sham-operated animal after perfusion fixation demonstrating normal structure (grade 0). The well-preserved neurons contain characteristic large, rounded nuclei with a dispersed chromatin pattern and conspicuous nucleoli. The neuronal perikarya retain their typical pyramidal configuration. Hematoxylin and eosin, $\times 250 . B$, Photomicrograph of cerebral neocortex demonstrating an isolated necrotic neuron from a grade 1 lesion (arrow). Compared with adjacent normal neurons, the ischemic neuron is shrunken and dark. Hematoxylin and eosin, $\times 250$. Inset, Higher magnification of isolated necrotic neuron demonstrating nuclear pyknosis and cytoplasmic retraction. The presence of nuclear pyknosis and cytoplasmic eosinophilia distinguishes such a cell from the occasional "dark" neuron that may occur in gray matter after mechanical manipulation. Hematoxylin and eosin, $\times 500$.

were used to categorize each piglet as either normal; encephalopathic of either mild, moderate, or severe involvement; or brain dead. This categorization corresponds to the original OPS classification described as normal, moderate impairment, severe impairment, vegetative, and brain dead (12). Mild encephalopathic changes consisted of partial awareness; difficulty with ambulation; possible seizures; and intact response to noise, pain, and light. Moderate encephalopathic changes consisted of partial awareness, inability to ambulate, running movements, hyperventilation, possible seizures, and intact response to pain. Severe encephalopathic changes consisted of unawareness; inability to stand, sit, or right itself; seizures; opisthotonic posturing; and reflex response to noise, pain, and light.

Brain histologic analysis. After $72 \mathrm{~h}$, animals were intubated, ventilated, and immobilized with appropriate analgesia. Catheters were placed cephalad in both common carotid arteries after ligation of the external carotid arteries to provide vascular access for brain perfusion and fixation. Both internal and external jugular veins were catheterized to provide a route of drainage during perfusion. The brain was perfused with Joklick's medium via bilateral intracarotid perfusion $(400-500 \mathrm{~mL})$ and then fixed with $0.125 \%$ glutaraldehyde and $2.0 \%$ paraformaldehyde in Sorenson's buffer $(500 \mathrm{~mL})$ at a constant pressure of $12 \mathrm{kPa}$. On completion of perfusion-fixation the brain was removed and immersed in a $10 \%$ solution of phosphate-buffered formalin for at least $2 \mathrm{wk}$. After immersion fixation, the brains were cut in five axial sections at approximately 5-, 10-, 15-, 20-, and 25-mm depths from the superior surface of the cortex. Axial sections were dehydrated in sequentially graded solutions of alcohol, chloroform, and xylene and embedded in Paraplast-R-paraffin compound. Embedded brain was sectioned en bloc at thicknesses of 6-8 $\mu \mathrm{m}$ and stained with hematoxylin and eosin. Brains were perfused and fixed identically to the above for six animals that either died prematurely or in whom the experimented was ended early because death appeared to be imminent before $72 \mathrm{~h}$ after ischemia. Brains perfused after death $(n=3)$ were not fixed as well compared with brains perfused with an intact circulation. However, the ischemic neuronal changes described below were easily discernible because the effects of autolysis and artefactual changes from poor fixation do not mimic the regressive neuronal changes associated with ischemia (13).

The extent of histologic ischemic neuronal damage was evaluated by a neuropathologist (D.K.B.) blinded to group assignment. Evidence of ischemic neuronal injury included nuclear pyknosis and karyolysis and cytoplasmic retraction and eosinophilia. The presence or absence of neuropil vacuolation and capillary endothelial swelling were also noted. Brains were scored on a scale of 0 to 4 , where $0=$ normal neuronal structure, $1=$ scattered isolated ischemic neurons, $2=$ groups of ischemic neurons, $3=$ laminar necrosis, and $4=$ ischemic changes in almost all or all neurons. Brain regions scored included neocortex (representing an average score of frontal, parietal, temporal, and occipital cortex from each of the first two axial sections beneath the brain surface), hippocampus, caudate nucleus, thalamus, cerebellum, midbrain, pons, and medulla. A composite histologic score was derived from the sum of scores of each region of brain examined using the scoring scale of $0-4$. For example, each axial section of neocortex had a maximal score of 32 because frontal, parietal, temporal, and occipital regions are assessed on the right and left side. The composite score is therefore the sum of scores for the two axial sections of neocortex, right and left sides of hippocampus, caudate nucleus, and thalamus and single sections of cerebellum, midbrain, pons, and medulla. The maximal composite score for a brain showing diffuse neuronal necrosis in all structures is 104.

Statistical analysis. A repeated measures analysis of variance (BMDP subprogram 5V) was used to compare physiologic and biochemical variables of the normothermic and modestly hypothermic groups (14). Results were considered significant if $p<$ 0.05 for group and time effects and $p<0.10$ for group-time interaction. Bonferroni-adjusted multiple comparisons were made to localize significant time effects using $p<0.0033$ and group-time interaction using $p<0.0028$. Comparison of OPS stages between groups were performed using a one-sided exact linear-by-linear test. Brain tissue structure was compared between groups by a one-sided Mann-Whitney test. Correlation 

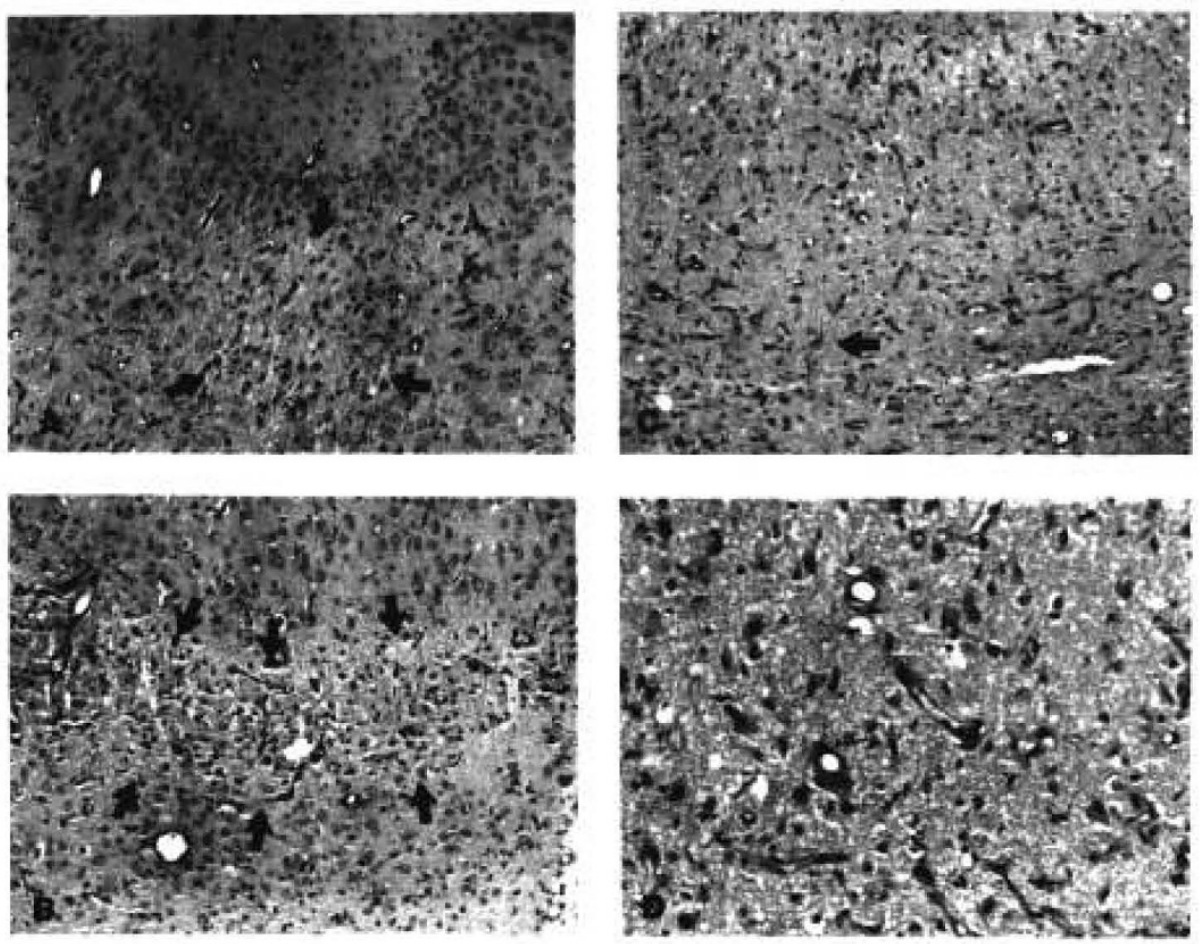

Fig. 3. $A$, Photomicrograph of small group of necrotic neurons from a grade 2 lesion. Multiple contiguous neurons exhibit characteristic nuclear pyknosis and cytoplasmic retraction (arrows). Hematoxylin and eosin, $\times 125$. B. Photomicrograph of neocortex from an animal with a grade 3 lesion. Laminar cortical necrosis is manifested by a linear zone of necrotic neurons involving the intermediate region of the cortical mantle (arrows), with sparing of the more superficial and deep neuronal layers. Hematoxylin and eosin, $\times 125$. $C$. Photomicrograph of a globally necrotic segment of cerebral cortex. Virtually all neurons exhibit cytoplasmic eosinophilia and loss of nuclear staining (arrow). Hematoxylin and eosin, $\times 125$. $D$, Higher magnification of a globally necrotic cortical segment containing no viable neurons, in contrast to normal cortex shown in Figure $2 A$. Also evident is vacuolation of the neuropil. Hematoxylin and eosin, $\times 250$.
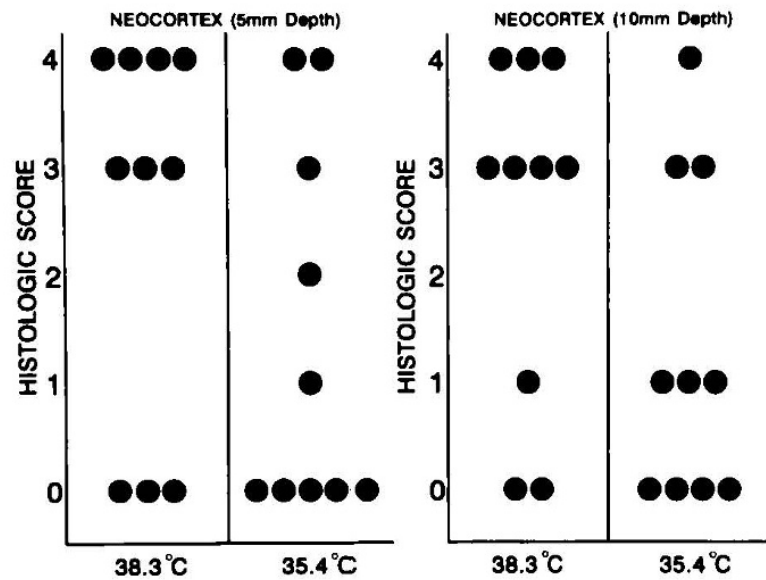

Fig. 4. The effects of temperature on the grade of histologic injury for normothermic $\left(38.3^{\circ} \mathrm{C}\right)$ and modestly hypothermic $\left(35.4^{\circ} \mathrm{C}\right)$ groups from axial sections of brain at depths of $5 \mathrm{~mm}$ and $10 \mathrm{~mm}$ beneath the cortical surface. The results represent an average score of frontal, parietal, temporal, and occipital cortex surveyed within each axial section. Each symbol represents an individual animal. Groups are different at $5 \mathrm{~mm}$ $(p=0.048)$ and trends in the same direction at $10 \mathrm{~mm}(p=0.07)$.

between brain histologic scores and OPS were assessed using Spearman's correlation. All results are expressed as mean \pm SD.

\section{RESULTS}

Relationship between brain and rectal temperature. Preliminary studies in four piglets delineated the relationship between brain and rectal temperature during ischemia. Before ischemia, brain temperature was $0.3 \pm 0.4^{\circ} \mathrm{C}$ lower than rectal temperature at a depth of $2 \mathrm{~cm}$ (NS). However, brain temperature was $0.7 \pm$ $0.6^{\circ} \mathrm{C}$ lower than rectal temperature at a depth of $1 \mathrm{~cm}(p<$ 0.025 ), indicating the presence of a temperature gradient from deep brain to the surface. The difference between rectal and brain temperature at either depth remained constant for rectal temperatures between $35.5-39.6^{\circ} \mathrm{C}$. However, during ischemia when rectal temperature was maintained constant at either $39.5-40^{\circ} \mathrm{C}$ or $35-35.5^{\circ} \mathrm{C}$ (Fig. 1), brain temperature was reduced, resulting in a dissociation between rectal and brain temperature. The magnitude of dissociation in brain temperature in animals with rectal temperature maintained at either $39.5^{\circ} \mathrm{C}$ or $35.5^{\circ} \mathrm{C}$ was similar at a depth of $1 \mathrm{~cm}$ but was modestly but significantly greater at the $2 \mathrm{~cm}$ depth $(p<0.025)$ in hypothermic animals. Thus, during ischemia the difference in brain temperature between groups with different rectal temperatures is at least the same or greater than the group differences in rectal temperature. Thus, intraischemic differences in rectal temperature can be used as an indicator of different brain temperatures.

After reinfusion of all withdrawal blood and deflation of the neck cuff, brain temperature recorded from 1- and 2-cm depths rose rapidly in all animals. At 5, 10, and $15 \mathrm{~min}$ after blood reinfusion (Fig. 1, arrow), the difference in temperature between the rectum and brain at either depth was of similar magnitude in animals with a rectal temperature maintained at either $39.5^{\circ} \mathrm{C}$ or $35.5^{\circ} \mathrm{C}$. By $10 \mathrm{~min}$ after blood reinfusion $(13 \mathrm{~min}$ after ischemia), brain and rectal temperature closely approximated each other, and this pattern was independent of the absolute value of the rectal temperature. Rewarming of modestly hypothermic piglets to normothermia at a time remote from ischemia (data not shown) was characterized by parallel increases in rectal and brain temperature.

Physiologic and biochemical changes. During ischemia distinct rectal temperatures occurred between groups $\left(2.9^{\circ} \mathrm{C}\right.$ difference, Table 1). Our objective was to limit group temperature differ- 

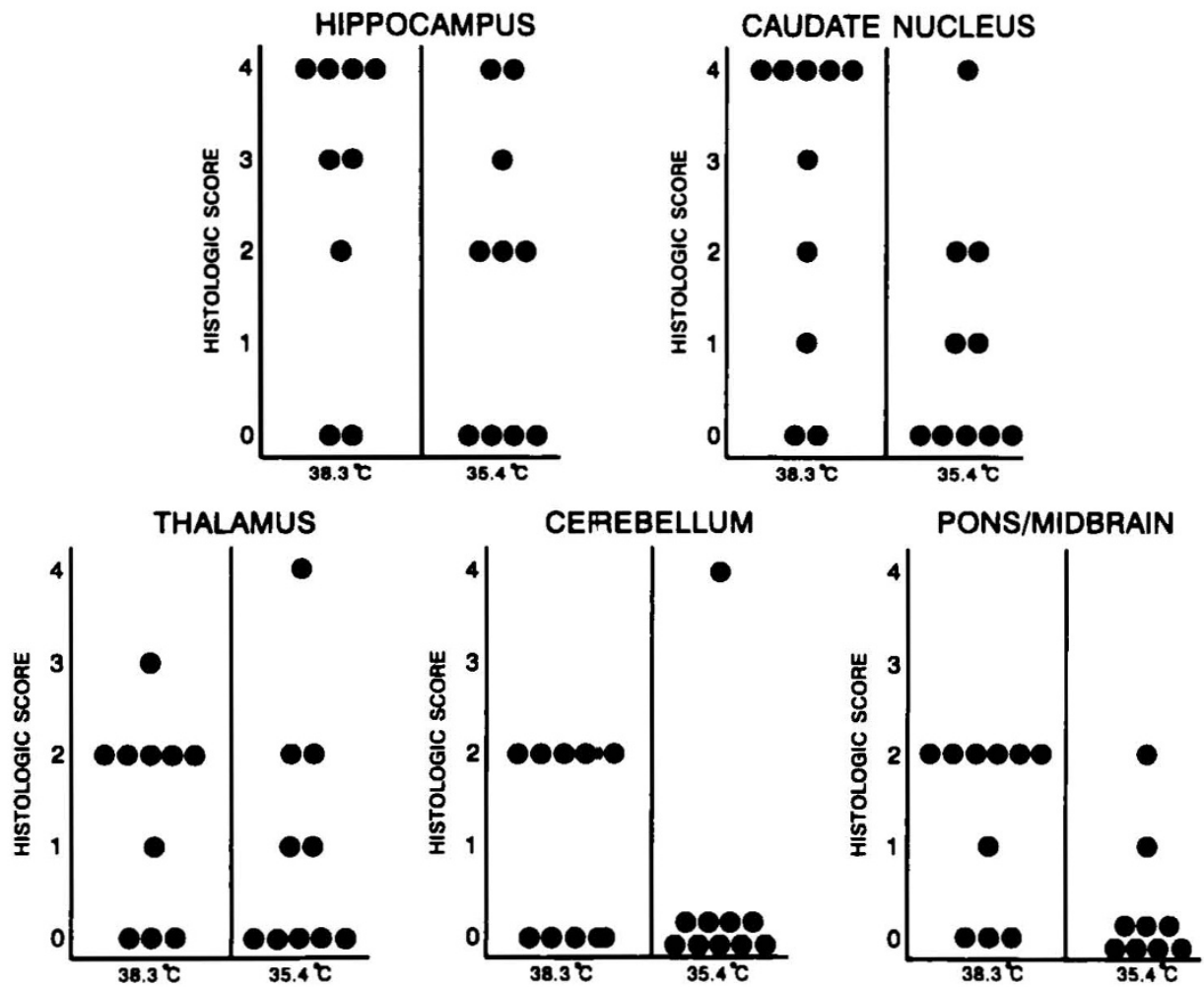

Fig. 5. The effect of temperature on the grade of histologic injury for the hippocampus, caudate nucleus, thalamus, cerebellum, and pons/ midbrain for normothermic $\left(38.3^{\circ} \mathrm{C}\right)$ and modestly hypothermic $\left(35.4^{\circ} \mathrm{C}\right)$ animals. Group comparisons are as follows: hippocampus $(p=0.11)$, caudate nucleus $(p=0.038)$, thalamus $(p=0.15)$, pons/midbrain $(p=0.04)$, and cerebellum $(p=0.07)$.

ences to ischemia, but differences were still present 5 min after ischemia. In a subgroup of five piglets in each group, an additional rectal temperature was recorded at 12 min after ischemia and indicated decreasing group differences $\left(37.6 \pm 0.6^{\circ} \mathrm{C}\right.$ for normothermic, $36.5 \pm 0.7^{\circ} \mathrm{C}$ for hypothermic). At $5 \mathrm{~min}$ after ischemia rectal temperature fell in normothermic animals ( $p=$ 0.0005 versus control) and presumably reflects heat dissipation from previously ischemic tissue beds on reperfusion. MAP did not differ between groups during the study. Postischemia MAP was restored to control values except at $60 \mathrm{~min}(p<0.0001)$. There was a group-time interaction for heart rate $(p<0.001)$. The heart rate of normothermic animals at control was $249 \pm$ 45 beats/min and increased to $292 \pm 26$ and $283 \pm 19$ beats/ min at 4 and $12 \mathrm{~min}$ of ischemia. The heart rate of modestly hypothermic animals was $248 \pm 50$ beats/min at control and decreased to $230 \pm 39$ beats $/ \mathrm{min}$ and $226 \pm 37$ beats $/ \mathrm{min}$ at 4 and $12 \mathrm{~min}$ of ischemia $(p<0.0001$ versus normothermic for both values). After ischemia heart rate was similar between groups.

Arterial pH was similar between groups at each study interval (Table 1). At each time interval after ischemia arterial $\mathrm{pH}$ remained less than control $(p<0.0001$ for both normothermia and hypothermia, respectively). Arterial carbon dioxide tension was similar between groups at each study interval with mean values for each group varying between $4.4 \pm 1$ to $5.4 \pm 1 \mathrm{kPa}$ and $4.0 \pm 1$ to $5.1 \pm 1 \mathrm{kPa}$ for normothermic and hypothermic groups, respectively. Arterial oxygen tension was greater than 13 $\mathrm{kPa}$, did not vary over time, and was comparable between groups. A group-time interaction was present for arterial lactate concentration $(p=0.014)$ with a difference between groups at $30 \mathrm{~min}$ after ischemia ( $p=0.0033)$. A trend for a group effect existed $(p=0.055)$, indicating lower arterial lactate concentration in modestly hypothermic compared with normothermic animals during and after ischemia. Arterial glucose concentration (data not shown) was similar between groups throughout the study. In the three sham-operated animals, two were maintained normo- thermic and one was made modestly hypothermic for a 30 -min interval. Serial assessment of MAP, heart rate, $\mathrm{pH}$, blood gases, and plasma concentrations of lactate and glucose were unchanging.

At $72 \mathrm{~h}$ after ischemia, physiologic and biochemical variables were measured in 10 piglets ( 5 in each group). There were no group differences and no differences from control for heart rate, MAP, arterial $\mathrm{pH}$, arterial carbon dioxide tension, arterial oxygen tension, hematocrit values, and plasma concentrations of lactate and glucose. Measurements were not routinely obtained from the remaining animals because of premature death $(n=6)$ or malfunction of the arterial catheter. In three of the severely encephalopathic piglets arterial $\mathrm{pH}, \mathrm{Po}_{2}$, and $\mathrm{PCO}_{2}$ were measured shortly before premature death and were $7.45 \pm 0.07 \mathrm{kPA}, 14.5$ $\pm 6 \mathrm{kPa}$, and $4.1 \pm 0.1 \mathrm{kPa}$, respectively.

$O P S$. The OPS for each group is listed in Table 2 and represent the worst OPS score for each animal. A significant pattern toward more severe OPS was observed in the normothermic as compared with the modestly hypothermic group $(p=0.023$ for a one-sided alternative). Of the 10 animals with OPS scores indicating encephalopathy, four piglets ( 2 in each group) progressed to a more severe OPS category. These animals progressed from normal to mild encephalopathy $(n=2)$, mild to moderate encephalopathy $(n=1)$, and moderate to severe encephalopathy $(n=1)$. The remaining six animals had the same OPS score at each evaluation after ischemia. Thus, OPS classification at $24 \mathrm{~h}$ after ischemia identified eight of 10 piglets with some degree of neurologic impairment. Progression to the final OPS category always occurred by $48 \mathrm{~h}$ after ischemia. Six piglets died before the 72-h evaluation, and all were in a severe encephalopathic state. Three of the six piglets were severely encephalopathic by late afternoon and died during the night (between 30 and $40 \mathrm{~h}$ after ischemia). For the subsequent three piglets who fulfilled the criteria for severe encephalopathy, death was deemed to be imminent (characterized by presence of seizures and apnea), and the animals were instrumented for brain perfusion-fixation at approximately 
$24 \mathrm{~h}$ after ischemia in two piglets and at $48 \mathrm{~h}$ after ischemia in one piglet.

Histologic evaluation. Examples of the histologic appearance of the brain is provided in Figures 2 and 3. Histologic examination of all three sham-operated animals revealed normal neuronal structure. The results of the histologic scores for normothermic and modestly hypothermic animals from axial sections at $5 \mathrm{~mm}$ and $10 \mathrm{~mm}$ beneath the cortical surface are displayed in Figure 4. The extent of involvement among the four regions of cortex (frontal, parietal, temporal, and occipital) was homogenous for a given piglet. For axial sections at a depth of $5 \mathrm{~mm}$, the normothermic group had a greater number of animals with more severe neuronal damage than the modestly hypothermic group $(p=0.048)$. The same direction of effect was found in axial sections at a depth of $10 \mathrm{~mm}(p=0.07)$. In modestly hypothermic animals less severe neuronal damage (Fig. 5) was present in the caudate nucleus $(p=0.038)$ and pons/midbrain $(p=0.04)$ and a similar direction of effect for the cerebellum ( $p$ $=0.07$ ). No differences were noted between groups for the hippocampus and thalamus. No damage was noted in the medulla of either group. Linear correlations between the maximal OPS and brain tissue structure were explored in one of two ways: l) a composite histologic score was derived on the basis of all brain structures examined and revealed an $r=0.65(p=0.041)$ for normothermic piglets and an $r=0.81(p=0.005)$ for modestly hypothermic piglets, or 2) a composite histologic score was derived on the basis of only the axial sections of cortex (sections at 5 and $10 \mathrm{~mm})$, which revealed an $r=0.76(p=$ $0.011)$ for normothermic piglets and an $r=0.84(p=0.002)$ for modestly hypothermic piglets. The composite histologic scores for all brain structures were $56.6 \pm 36.6$ (range, $0-88$ ) and 30.3 \pm 32.0 (range, $0-94$ ) for normothermic and modestly hypothermic groups, respectively. Composite scores based only on the axial sections of neocortex were $41.6 \pm 27.2$ (range, $0-64$ ) and $21.8 \pm 24.4$ (range, $0-62$ ) for normothermic and modestly hypothermic groups, respectively. Correlations were also performed between OPS at $24 \mathrm{~h}$ after ischemia and brain histologic analysis. Each of the eight piglets with OPS scores other than normal at $24 \mathrm{~h}$ after ischemia had histologic evidence of brain damage. The correlation between the composite histologic score and 24-h OPS was an $r=0.68(p=0.03)$ for normothermic piglets and an $r=$ 0.29 for modestly hypothermic piglets. Lack of a correlation for modestly hypothermic piglets reflects that only one animal was neurologically impaired at $24 \mathrm{~h}$ after ischemia.

\section{DISCUSSION}

This investigation established that the experimental paradigm used to induce partial brain ischemia resulted in clinical and histopathologic evidence of ischemic neuronal injury. The brain temperature results demonstrated that experimental groups with different intraischemic rectal temperatures had distinct brain temperatures during ischemia. The latter result obviated an absolute necessity for measurement of brain temperature and facilitated conducting an experiment with chronically instrumented animals for a span of $5 \mathrm{~d}$. This model was used to test the hypothesis that small reductions in brain temperature may have important neuroprotective effects. The results support this contention by demonstrating that a reduction in rectal temperature of only $2.9^{\circ} \mathrm{C}$ during partial brain ischemia was associated with less clinical and histopathologic evidence of ischemic neuronal injury. This conclusion is consistent with recent observations regarding neuroprotection of modest hypothermia during ischemia in adult rats $(3,6,15)$, gerbils $(4)$, and dogs $(5,12)$. In the latter investigations modest hypothermia was used in a protective manner, i.e. temperature reductions were initiated before ischemia and continued during the ischemic interval. The aim of our investigation was also to study the use of modest hypothermia in a protective mode. However, group differences in temperature persisted in the first $15 \mathrm{~min}$ after ischemia, and therefore potential benefits of modest hypothermia as a resuscitative therapy is possible. Presumably group differences in temperature after ischemia reflect the limitations of rapidly rewarming swine (1-2 kg body weight) compared with rats and gerbils (0.2-0.4 $\mathrm{kg}$ body weight).

Busto et al. (3) demonstrated regional brain sensitivity in adult rats for the ischemic neuroprotection of modest hypothermia. Brain regions such as the neocortex and thalamus demonstrated less neuroprotection than the central striatum, dorsolateral striatum, and hippocampus. These results were confirmed by Minamisawa $e t$ al. (16) with a similar method of inducing ischemia in adult rats. The caudoputamen and the subiculum and CA-1 sector of hippocampus were temperature-sensitive regions, whereas cortex and thalamus demonstrated less benefit, and substantia nigra appeared to be temperature insensitive. These results were observed despite methodologic differences in controlling brain temperature (17). The present investigation also demonstrated regional sensitivity for the neuroprotective effects of modest hypothermia. Modest hypothermia was associated with less neuronal injury in the caudate nucleus and neocortex compared with the normothermic group in contrast to similar histologic scores between groups of thalamus and hippocampus. The results for piglet hippocampus clearly differ from studies of adult hippocampus in rats $(3,16,18)$, gerbils $(4,19,20)$, and rabbits (21), although an obvious explanation is not apparent.

This investigation does not address a specific mechanism for the observed neuroprotective effects of modest hypothermia. The experiment was designed to result in identical MAP during ischemia and presumably similar reductions in CBF. It remains possible that modest hypothermia moderated the extent of $\mathrm{CBF}$ reduction and the severity of ischemia. Differences in heart rate during ischemia demonstrate that modest hypothermia was associated with alterations in variables that may influence systemic and potentially cerebral hemodynamics. Whether the trend for group differences in arterial lactate concentration during and after ischemia reflect altered hemodynamics or the effects of hypothermia on glycolytic flux remains unclear (22). Further investigation will be necessary to define the effects of intraischemic modest hypothermia on $\mathrm{CBF}, \mathrm{O}_{2}$ consumption, and energy use and to determine if any of these effects mediate the neuroprotection associated with modest hypothermia.

It is possible that the extent of brain damage may be determined in part by postischemic events such as alterations in systemic physiologic-biochemical variables, reperfusion-reoxygenation injury, or both (23). Because postischemic systemic variables were not routinely evaluated in this study, no way exists of testing whether group differences in neuropathologic conditions reflect differences in postischemic physiologic stability of the two groups. However, arterial $\mathrm{pH}$ and blood gases were measured in three severely encephalopathic piglets shortly before premature death (see Results). The $\mathrm{pH}$ values did not reveal a profound metabolic acidosis indicative of postischemic cardiovascular instability. Furthermore, if group differences in neuropathologic conditions were possibly related to postischemic physiologic stability, group differences would still reflect (albeit indirectly) the experimental conditions of each group during ischemia. An interesting characteristic of this brain ischemia model is an association between animal age and the presence of brain damage. Age range in each group was 5-13 d. Animals with a normal OPS (both normothermic and hypothermic, $n=$ 10) had a mean age of $8 \pm 2 \mathrm{~d}$, which differed from the 10 piglets with an OPS indicating encephalopathy $(11 \pm 3$ days, $p<0.05)$. This observation is consistent with prior reports of enhanced tolerance of younger mammals during hypoxia-ischemia (24). This association did not influence the observed differences between normothermic and modestly hypothermic groups because pairs of piglets from the same litter were studied on the same day, with one piglet for each experimental group.

The results of this study clearly justify further investigation of modest hypothermia as a therapy to provide neuroprotection. 
This investigation has specifically focused on the use of modest hypothermia during ischemia and may be of relevance for some delivery room events and intervals of prolonged cardiovascular instability in the neonatal intensive care unit (e.g. persistent pulmonary hypertension) where a protective stategy may be feasible. Potentially even greater clinical relevance may exist if modest hypothermia is efficacious as a resuscitative therapy. Modest hypothermia as a neuroprotective therapy must be critically assessed relative to well-recognized adverse effects of cold exposure $(25,26)$ and the critical importance of the thermal environment for the neonate. Whether short intervals of modest hypothermia would be associated with adverse systemic effects remains unanswered. The latter remains a concern because a prominent redistribution of cardiac output in response to a cold stress occurs even when a successful homeothermic response occurs (27). Furthermore, four prospective, randomized clinical trials demonstrated that low birth weight infants nursed in warmer compared with cooler thermal environments over the first $5 \mathrm{~d}$ of live have reduced mortality (28-31). These observations provide the basis for thermoregulatory management for all low-birth-weight and sick term neonates and has been extrapolated to resuscitation of newborns in the delivery room where the first principle is to prevent excessive heat loss (32). There are prior reports describing benefit from the use of mild and profound hypothermia as an adjunct for resuscitation of infants with birth asphyxia in whom conventional measures were ineffective $(33,34)$. However, these reports were uncontrolled clinical experiences and further justify a more rigorous, systematic evaluation of modest hypothermia as a neuroprotective maneuver.

Acknowledgment. The authors thank Marilyn Dixon for her secretarial expertise.

\section{REFERENCES}

1. Rosomoff HL 1959 Protective effects of hypothermia against pathological processes of the nervous system. Ann NY Acad Sci 80:475-486

2. Kopf GS, Mirvis DM, Myers RE 1975 Central nervous system tolerance to cardiac arrest during profound hypothermia. J Surg Res 18:29-34

3. Busto R, Dietrich WD, Globus MY-T, Valdes I, Scheinberg P, Ginsberg MD 1987 Small differences in intraischemic brain temperature critically determine the extent of ischemic neuronal injury. J Cereb Blood Flow Metab 7:729-738

4. Welsh FA, Sims RE, Harris VA 1990 Mild hypothermia prevents ischemic injury in gerbil hippocampus. J Cereb Blood Flow Metab 10:557-563

5. Natale JE, D'Alecy LG 1989 Protection from cerebral ischemia by brain cooling without reduced lactate accumulation in dogs. Stroke 20:770-777

6. Minamisawa H, Nordstrom CH, Smith ML, Siesjo BK 1990 The influence of mild body and brain hypothermia on ischemic brain damage. J Cereb Blood Flow Metab 10:365-374

7. Young RSK, Olenginski TP, Yagel SK, Towfighi J 1983 The effect of graded hypothermia on hypoxic-ischemic brain damage: a neuropathologic study in the neonatal rat. Stroke 14:929-934

8. Ikonomidou C, Mosinger JL, Olney JW 1989 Hypothermia enhances protective effect of MK801 against hypoxic-ischemic brain damage in infant rats. Brain Res 487:184-187

9. Dahm LS, James LS 1972 Newborn temperature and calculated heat loss in the delivery room. Pediatrics 49:504-513
10. Laptook AR, Corbett RJT, Nguyen HT, Peterson J, Nunnally RL 1988 Alterations in cerebral blood flow and phosphorylated metabolites in piglets during and after partial ischemia. Pediatr Res 23:206-211

11. Laptook AR. Corbett RJT, Arencibia-Mireles O, Ruley J 1992 Glucose associated alterations in ischemic brain metabolism of neonatal piglets. Stroke 23:1504-1511

12. Leonov Y, Sterz F, Safar P, Radovsky A, Oku J, Tisherman S, Stezoski SW 1990 Mild cerebral hypothermia during and after cardiac arrest improves neurologic outcome in dogs. J Cereb Blood Flow Metab 10:57-70

13. Brown AW, Brierley JB 1968 The nature, distribution and earliest stages of anoxic-ischaemic nerve cell damage in the rat brain as defined by the optical microscope. Br J Exp Pathol 49:87-106

14. Dixon WS, Brown MB, Engelman L, Jennrich RI 1990 BMDP Statistical Software Manual. Vol 2. University of California Press, Berkeley

15. Busto R, Dietrich WD, Globus MY-T, Ginsberg MD 1989 The importance of brain temperature in cerebral ischemic injury. Stroke 20:1113-1114

16. Minamisawa H, Smith MJ, Siesjo BK 1990 The effect of mild hyperthermia and hypothermia on brain damage following 5,10 , and 15 minutes of forebrain ischemia. Ann Neurol 28:26-33

17. Minamisawa $H$, Mellergard $P$, Smith ML, Bengstsson $F$, Theander $S$, BorisMoller F, Siesjo BK 1990 Preservation of brain temperature during ischemia in rats. Stroke 21:758-764

18. Green EJ, Dietrich WD, van Dijk F, Busto R, Markgraf CG, McCabe PM, Ginsberg MD, Schneiderman N 1992 Protective effects of brain hypothermia on behavior and histopathology following global brain ischemia. Brain Res 580:197-204

19. Yamashita K, Eguchi $Y$, Kajiwara K, Ito H 1991 Mild hypothermia ameliorates ubiquitin synthesis and prevents delayed neuronal death in the gerbil hippocampus. Stroke 22:1574-1581

20. Churn SB, Taft WC, Billingsley MS, Blair RE, DeLorenzo RJ 1990 Temperature modidation of ischemic neuronal death and inhibition of calcium/ calmodulin-dependent protein kinase II in gerbils. Stroke 21:1715-1721

21. Baker AJ, Zornow MH, Grafe MR, Scheller MS, Skilling SR, Smullin DH, Larson AA 1991 Hypothermia prevents ischemia-induced increase in hippocampal glycine concentrations in rabbits. Stroke 22:666-673

22. Hagerdal M, Harp J, Siesjo BK 1975 Effect of hypothermia upon organic phosphates, glycolytic metabolites, citric acid cycle intermediates, and associated amino acids in rat cerebral cortex. J Neurochem 24:743-748

23. Vannucci RC 1990 Experimental biology of cerebral hypoxia-ischemia: relation to perinatal brain damage. Pediatr Res 27:317-326

24. Duffy TE, Kohle SJ, Vannucci RC 1975 Carbohydrate and energy metabolism in perinatal rat brain: relation to survival in anoxia. J Neurochem 24:271276

25. Mann TP 1955 Hypothermia in the newborn: a new syndrome? Lancet 1:613614

26. Mann TP, Elliott RIK 1957 Neonatal cold injury due to accidental exposure to cold. Lancet 1:229-233

27. Mayfield SR, Stonestreet BS, Brubakk AM, Shaul PW, Oh W 1986 Regional blood flow in newborn piglets during environment cold stress. Am J Physiol 251:G308-G313

28. Silverman WA, Fertig JW, Berger AP 1958 The influence of the thermal environment upon the survival of newly born premature infants. Pediatrics 22:876-885

29. Jolly $\mathrm{H}$, Molyneux P, Newell DJ 1962 A controlled study of the effect of temperature on premature babies. J Pediatr 60:889-894

30. Day RL, Caliguiri L, Kamenski C, Ehrlich F 1964 Body temperature and survival of premature infants. Pediatrics $34: 171-181$

31. Buetow KC, Klein SW 1964 Effect of maintenance of "normal" skin temperature on survival of infants of low birth weight. Pediatrics 34:163-170

32. Bloom RS, Cropley C 1990 Initial steps in resuscitation. In: Chameides L (ed) Textbook of Neonatal Resuscitation. American Heart Association and American Academy of Pediatrics, Elk Grove, IL, pp 2-1-2-48

33. Miller JA, Miller FS, Westin B 1964 Hypothermia in the treatment of asphyxia neonatorum. Biol Neonat 6:148-163

34. Cordey R, Chiolero R, Miller JA 1973 Resuscitation of neonates by hypothermia: report on 20 cases with acid-base determination on 10 cases and the long term development of 33 cases. Resuscitation 2:169-181 